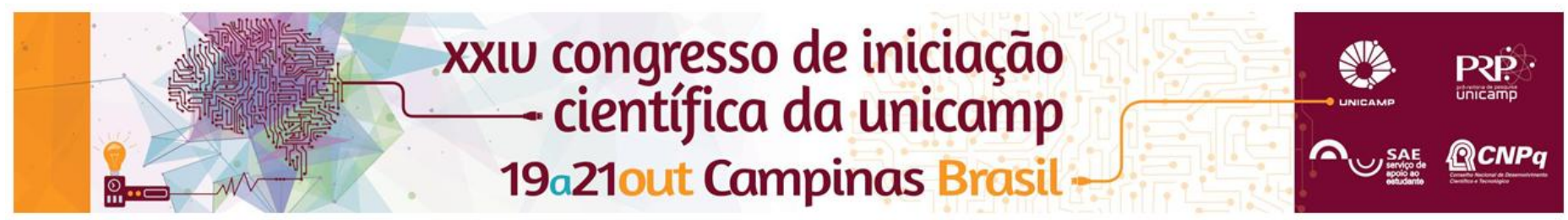

\title{
Demandas de atividades físicas dos times vencedores e perdedores no basquetebol de alto rendimento no Brasil.
}

\author{
Renê A. Ribeiro*, Luciano A. Mercadante
}

\begin{abstract}
Resumo posições dos jogadores.

Palavras-chaves: Basquetebol, esforços físicos, atividade física.

\section{Introdução}

Poucas propostas são apresentadas na literatura para descrever, quantificar e qualificar as ações realizadas por jogadores de basquetebol, em função do esforço físico que representam. [1], descreveram as ações em um jogo, considerando deslocamentos horizontais, saltos movimentações na posição de defesa, e movimentações de braços. Concluíram que os armadores e alas realizam mais esforços que os pivôs, porém, não consideraram as forças de contato corporal, muito comuns para os pivôs. O objetivo deste trabalho foi validar e aplicar nova classificação das ações para os jogos de basquetebol, verificar as diferenças entre as funções dos jogadores.
\end{abstract}

Poucas propostas são apresentadas na literatura para descrever, quantificar e qualificar as ações realizadas por jogadores de basquetebol, separando-as a partir do esforço físico e gasto de energia que ela representa. Assim, o presente trabalho tem como objetivo aplicar e validar uma nova classificação das demandas de atividades físicas físicas dos times vencedores e perdedores no basquetebol de alto rendimento no Brasil. A proposta foi aplicada no Novo Basquete Brasil da temporada 2011/2012. Os dados foram coletados e analisados utilizando o Sistema Dvideo® e as comparações estatísticas foram realizadas em ambiente Matlab®. Foram discutidas possíveis diferenças entre as

\section{Métodos}

O registro foi realizado no principal campeonato brasileiro masculino por filmagem controlada, feito com quatro câmeras localizadas nos cantos superiores do ginásio, de forma a enquadrar toda a quadra.

As ações foram quantificadas pela sua frequência, duração total e média, utilizando o módulo scout do Sistema Dvideo [2], que permite quantificar a ocorrência de cada ação e definir frame a frame o início, fim e o jogador que a realizou. Os dados coletados foram tratados em ambiente Matlab ${ }^{\circledR}$. A classificação proposta considera: os deslocamentos horizontais no plano da quadra, com as subclasses para frente, para trás, para as laterais, na posição defensiva e parado; os deslocamentos verticais, quando um jogador perde 0 contato dos dois pés com o solo; as trocas de forças de contato, considerando as subclasses proteçã̃o de rebote, jogo 1x1, bloqueios e faltas; os dribles; e as movimentação dos membros superiores, que considerou os jogadores em posição de defesa com um ou os dois membros superiores acima da altura dos ombros.

As medições foram validadas por teste-reteste com a medida de concordância intra-avaliador a partir do índice Kappa de Cohen [3] e a classificação do índice seguindo os critérios de Landis e Koch [4]. O processo de medicação do teste foi realizado com um intervalo de um mês para o reteste.

Para as análises foram consideradas as posições/funções dos jogadores, e as mudanças de função durante os jogos, a partir da observação de experts e do técnico da equipe.

\section{Resultados e discussões}

A concordância intra-avaliador, mensurada pelo coeficiente de kappa, foi de 0.71 , considerando todas as ações, valor substancial segundo [4]. Quando separada a avaliação em dois blocos, (a) o primeiro contendo as ações de deslocamento horizontal, e, (b) o segundo as outras ações, os valores de Kappa foram 0.63 (substancial) e 0.85 (perfeito), respectivamente. Destaca-se a maior frequência média de ações/quarto das trocas de forças de contato dos pivôs e alas-pivôs $(22,6)$ em relação aos armadores, ala-amadores e alas $(10,7)$. Além disso, ocorreram em média, 3,3 dribles/quarto para os pivôs e ala-pivôs, e 10 dribles/quarto para os armadores, ala-amadores e alas.

\section{Conclusão}

Esse estudo apresentou nova forma de classificação das ações realizadas por jogadores durante jogos de basquetebol e mostrou a importância de considerar as trocas de forças de contato corporal para as diferentes funções/posições em quadra, além de validar a metodologia usada na coleta dos dados. Quanto a utilização da classificação em um quarto de um jogo de elite, existe uma necessidade de ampliação da amostra para melhores análises.

\section{Agradecimentos}

Conselho Nacional de Desenvolvimento Científico e Tecnológico (CNPq) e Liga Nacional Basquetebol (LNB).

1 FIGUEROA, P.J.; LEITE, N.; BARROS, R.M.L. A Flexible Software for Tracking of Markers used in Human Motion Analysis. Computer Methods and Programs in Biomedicine, v.72, p.155-165, 2003.

Games. The 33rd International Conference on Biomechanics in Sports 2 SCANLAN, A.; DASCOMBE, B.; REABURN, P. A comparison of the activity demands of elite and sub-elite Australian men's basketball competition. Journal of Sports Sciences, v.29, n.11, p. 1153-1160, 2011. 3 Cohen, J.A. Coefficient of Agreement for Nominal Scales. Educational and Psychological Measurement, 20, 37-46, (1960).

4 Landis J.R., Koch G.G. The meansurement of observer agreement for categorical data. Biometrics, 33, 159-174. (1977). 